\title{
Revisiting the anaesthesiologist's role during organ procurement
}

\author{
Gali Katznelson ${ }^{1,2}$, Hance Clarke ${ }^{2,3}$ \\ ${ }^{1}$ Harvard Medical School, Center for Bioethics, Boston, MA, USA \\ 2Pain Research Unit, Department of Anaesthesia and Pain Medicine, Toronto General Hospital, \\ University Health Network, Toronto, Ontario, Canada \\ ${ }^{3}$ Department of Anaesthesia, University of Toronto, Toronto, Ontario, Canada
}

\begin{abstract}
As organ transplantation science continues to mature, both physicians and the public face challenges defining death and, subsequently, caring for an individual when they are deemed eligible for organ procurement. This paper revisits the anaesthesiologist's role with respect to the provision of analgesic medication at the time of organ procurement. It provides a historical overview of the ethics of organ procurement, explaining how the definition of brain death and the ethical principle of the'dead donor rule' have shaped the practice of organ procurement. It concludes by suggesting that a re-framing of the ethics of organ procurement may be necessary in order for anaesthesiologists to meet their ethical obligation of preventing harm to organ donors while maintaining public trust in the medical profession.
\end{abstract}

Anaesthesiology Intensive Therapy 2018, vol. 50, no 2, 91-94

Key words: organ procurement; analgesia

Anaesthesiologists administer analgesia to minimise painful sensations during medical procedures. They also employ medications to maintain proper oxygenation, heart function, blood pressure, cerebral and renal blood flow, as well maintain healthy metabolic changes, such as avoiding acidosis and electrolyte abnormalities. The goal of anaesthesia is to keep the patient alive during surgery, as well as to render the patient unconscious in order to minimise the pain of surgery. Some anaesthesiologists are also involved in procedures of organ procurement from organ donors. These procedures are performed on individuals who are declared brain dead under neurologic criteria and who are identified to be organ donors. The goal of the anaesthesiologist during an organ procurement procedure is less clear. Dead people do not need to be kept alive nor do they feel pain. A controversy exists, however, regarding whether anaesthesiologists should administer the analgesic fentanyl to patients who are brain dead during organ procurement.

The practice of administering pain medication to brain dead patients during organ procurement was debated in the literature in 2000 in the Journal of the Association of
Anaesthetists of Great Britain and Ireland [1]. This debate has remained relatively dormant since. Young and Matta sparked the controversy by criticizing the recommendations by the United Kingdom's (UK) Intensive Care Society, which stated that analgesia or sedation is not required for brain dead patients. Young and Matta's editorial suggested that the haemodynamic response observed during organ procurement could be a signal of physiologic distress, given the lack of conclusive electroencephalogram (EEG) evidence to suggest otherwise. To make their claim, the authors cited work by Wetzel et al. [2], who showed that brain dead organ donors had an increase in systolic pressure by a mean of 31 torr, diastolic pressure by a mean of 16 torr, and an increase in heart rate by 23 beats per min in response to surgical intervention. Wetzel et al. [3] presented several potential explanations for a pressor response without mediation by the brainstem, such as an intact spinal reflex arc. However, they also noted that the criteria for the declaration of brain death in the UK do not identify full cessation of all brainstem neurons, but merely a degree of loss of function or irreversible brainstem damage from which point brain death becomes 
inevitable. They identified two patients in their study whose cortical evoked responses suggested some partial brainstem function. Young and Matta cited further evidence to question the UK criteria of brainstem death, such as continued hypothalamus activity, retained EEG activity [4], brainstem auditory evoked potentials [5], and residual perfusion of the basal ganglia, thalamus and/or brainstem from single proton emission tomography [6].

Several authors responded to the editorial with varying views. Wace and Kai applauded Young and Matta [7]. Poulton and Garfield, however, were concerned that the administration of pain medication during organ procurement would "render a conscious mind unconscious for the purpose of organ harvest [and] could well be considered as an act of euthanasia" [8] These commentators proposed that a more reasonable approach would be a reassessment of the UK brainstem criteria, public discourse, and honesty in discussions with brain dead patients'families as doing otherwise would jeopardize the public's trust in the medical profession. Turner also responded to Young and Matta's editorial with similar concerns, explaining that encouraging volatiles and opioids would lead to an implication that they are meant to prevent noxious stimuli, in which case, the validity of brainstem assessments should be called into question [9]. Keep responded by suggesting that the only reasonable conclusion to the editorial is that the UK brainstem death criteria do not sufficiently account for the death of the entire brain stem. However, he argued the opposing position to the other commentators, suggesting that rather than disclose this information to the public and risk outcry, anaesthesiologists should proceed to anesthetise brain dead patients, at least until a reappraisal of the UK brainstem death criteria [10].

Recent UK guidelines still hold that brainstem death is equivalent to death [11]. Beyond considerations for a reappraisal of brain death criteria, this controversy raises several other ethical issues that this paper will address. The first issue is the duty to 'do no harm' to patients. The evidence cited by Young and Matta suggests that people who meet brain death criteria in the UK may have some capacity to feel pain. In a typical anaesthesia procedure, any anaesthesiologist operating on a patient without taking reasonable steps to ensure adequate pain management would be seriously breaching their duty to the patient and could have their professional license revoked. In the case of organ procurement, the anaesthesiologist's duty to the donor rests on whether the donor is defined as the anaesthesiologist's patient. If the person undergoing organ procurement is considered the anaesthesiologist's patient, then the failure to ensure adequate analgesia should be seen as a gross misconduct. If the person undergoing organ procurement is considered biologically dead, then it logically follows that the physician no longer has an obligation to this patient to prevent pain.
Under the current ethical framework of organ transplantation, along with guidelines that prohibit the administration of analgesia during organ procurement, the anaesthesiologist's duty to prevent harm to a donor is incompatible with the ethics of organ transplantation. Tracing the history of the ethics of organ procurement, and particularly what is known as the 'dead donor rule' will elucidate this tension.

\section{HISTORY OF ORGAN PROCUREMENT ETHICS}

Before the mid $20^{\text {th }}$ century, establishing death was a simple task. Patients were deemed dead when their circulatory and respiratory systems ceased to function. With the 1952 advances in mechanical ventilation, and the 1955 opening of the first intensive care unit in Stockholm, patients without spontaneous respiration who would have otherwise died, could now be kept alive [12]. Their living status, however, soon came into question.

In 1959, Wertheimer et al. [13] described the "death of the nervous system" to characterize their non-spontaneously breathing comatose patients, proposing that ventilation should be stopped if death of the nervous system could be clinically diagnosed and an absence of EEG activity could be shown. Later that year, Mollaret and Goulon coined the condition coma dépassé (beyond coma) to describe their comatose patients who had primary irremediable structural brain regions which were incapable of spontaneous breathing [14]. In 1967, the first organ transplant was performed [15], raising concerns such as whether the brain-damaged donor was dead at the time of the transplant. To address such concerns, in 1968, the Harvard Ad Hoc committee at Harvard Medical School published a seminal report to define irreversible coma, implying that irreversible coma was a sufficient criteria for biological death [16]. This report led to the Uniform Determination of Death Act in the United States, which was based on recommendations by the 1981 President's Commission to characterise death as either irreversible cessation of circulatory and respiratory functions, or irreversible cessation of all functions of the entire brain, including the brainstem [17]. Similarly, in the UK in 1976, guidelines were published to define brain death as complete and irreversible loss of brainstem function, at which point, a committee proposed that "further artificial support is fruitless and should be withdrawn" [18]. Eventually in the UK, brainstem death "became equivalent to the death of the individual" [19].

The emergence of brain death as a medical concept that is equated with death has been key in the progression of organ transplantation. It has ensured that the ethics of organ transplantation rest on the 'dead donor rule,' a commonly accepted ethical principle that serves two purposes, namely: 1) patients must not die by organ procurement, and 2) patients must be dead before organs are procured. The 
dead donor rule has become a central principle in organ procurement, with the belief that adherence to this rule will prevent physicians from causing death and will maintain the public's trust in the medical profession [20].

\section{THE ANAESTHESIOLOGIST'S ROLE}

The dead donor rule is central to the debate over the anaesthesiologist's role during organ procurement. Administering medication to relieve pain in brain dead donors treats them as living patients, and is therefore ethically problematic. A well-intentioned anaesthesiologist seeking to prevent harm to the donor is caught between this duty and the ethical obligation of treating the donor as dead.

A violation of the dead donor rule is also implicated in the maintenance of public trust in the medical profession, as highlighted in the commentaries to Young and Matta's editorial. One might imagine the distress a family member would feel in hearing that their loved one, who had been just declared dead, was now being treated with analgesic medication in order to reduce a painful stimulus during organ procurement surgery. Such information may stir public fears of organ transplantation programs and exacerbate worries such as the common fears that doctors "might hasten my death" or that they might "do something to me before I'm really dead" [21]. The confusion caused by administering pain medication to patients deemed legally dead may only further such misunderstanding of death and may compromise public faith in organ transplantation.

What are anaesthesiologists to do? Are they to potentially violate their professional guidelines by administering analgesia during organ procurement to patients declared dead, on the chance that these patients might feel pain? Alternatively, in an effort to maintain public trust by adhering to the dead donor rule, should anaesthesiologists refrain from administering fentanyl, or should they administer fentanyl without transparency, as suggested by Keep?

Though there is a very minute chance that patients declared dead by neurologic criteria can experience pain, a cautionary approach is the most ethically sound. An analogy can be made to Pascal's Wager, a philosophical argument presented in the seventeenth century by Blaise Pascal about man's belief in God [22]. Pascal argued that any rational person should live as though God exists and thus believe in God. If God does not actually exist, the person will have lost little comparing to the infinite loss of being sentenced to an eternity in Hell by not believing in God. If God does exist, the person may have gained infinitely through an eternity in Heaven [23]. This wager applied to the anaesthesiologist during organ procurement posits that anaesthesiologists should act as if the donor can feel pain and therefore they should administer fentanyl. The losses of administering fentanyl if the person cannot feel pain are minimal; there is no evidence that fentanyl affects the viability of transplantable organs. The gains of administering fentanyl to a donor with the capacity to feel any pain are substantial; preventing pain would fulfil the physician's duty of doing no harm. This should be done with transparency to patient families, as doing otherwise would erode public trust in the medical profession.

Certainly, admitting that brain dead organ donors might feel pain places the entire organ transplantation enterprise into question. Some might then argue that the potential harm to donors should halt the practice of organ transplantation altogether. Yet it is undeniable that organ donors, individuals who have severe and irreversible brain damage, have a significant capacity to save lives. The demand for organs greatly outweighs the supply, and each donor has the potential to save several lives. Shutting down the practice of organ transplantation would result in thousands of lives lost every year. A new ethical framework for organ donation should be seriously considered. This framework should centralise harm prevention to the donor and balance harm prevention with the utilitarian goal of increasing organs.

\section{RE-FRAMING THE ORGAN PROCUREMENT PATHWAY}

Dr. Miller and Dr. Truog propose a framework for ethically permissible organ procurement that does not rely on the dead donor rule [24]. The authors argue that in so far as it is ethically permissible to cause death by withdrawing life support, it is ethically permissible to procure organs prior to the withdrawal of ventilation. In this way, the patient's interests are not compromised by the procurement of organs since the decision to withdraw life support has already been made prior to being in the intensive care setting. They clarify that vital organ procurement must be "conditional on and subsequent in time to prior valid decisions to withdraw life sustaining treatment" [24]. This important ethical constraint ensures that patients are not harmed from the organ procurement itself, as the decision to withdraw life support is made independently of the decision to donate organs, and death is caused by the withdrawal of life support rather than by organ procurement. They also acknowledge that being "legally dead is not the same as being biologically dead" [24], a reality that the public is entitled to understand.

Under this ethical re-framing, organ donors can be treated as living beings rather than corpses, and the need to decide whether to mitigate harm by administering analgesia during organ procurement will become less contentious and more reliant on a palliative care approach. Anaesthesiologists should wager that although it is highly unlikely that patients declared dead by neurologic criteria will feel pain, the slight possibility of this scenario warrants administration of fentanyl to prevent the donor from experiencing 
any harm during the procurement. The public should be made aware of the anaesthesiologist's process during organ procurement. Under a new framework, physicians can engage families in honest and open conversations about the existing controversial evidence of bodily reflexes in organ procurement, and if the substitute decision maker decides to proceed with withdrawing life support, and then decides to donate the patient's organs, anaesthesiologists should feel comfortable administering analgesia during organ procurement.

\section{ACKNOWLEDGEMENTS}

1. Source of funding: none.

2. Conflict of interest: none.

\section{References:}

1. Young PJ, Matta BF. Anaesthesia for organ donation in the brainstem dead-why bother? Anaesthesia. 2000; 55(2): 105-106, indexed in Pubmed: 10651668.

2. Wetzel RC, Setzer N, Stiff JL, et al. Hemodynamic responses in brain dead organ donor patients. Anesth Analg. 1985; 64(2): 125-128, indexed in Pubmed: 3882020.

3. Howlett TA, Keogh AM, Perry L, et al. Anterior and posterior pituitary function in brain-stem-dead donors. A possible role for hormonal replacement therapy. Transplantation. 1989; 47(5): 828-834, indexed in Pubmed: 2718243.

4. Pallis $C . A B C$ of brain stem death. Prognostic significance of a dead brain stem. Br Med J (Clin Res Ed). 1983; 286(6359): 123-124, indexed in Pubmed: 6401485.

5. Machado C, Valdés P, García-Tigera J, et al. Brain-stem auditory evoked potentials and brain death. Electroencephalogr Clin Neurophysiol. 1991; 80(5): 392-398, indexed in Pubmed: 1716564.

6. Facco $E$, Zucchetta $P$, Munari $M$, et al. $99 \mathrm{mTc}-\mathrm{HMPAO}$ SPECT in the diagnosis of brain death. Intensive Care Med. 1998; 24(9): 911-917, indexed in Pubmed: 9803326.

7. Wace J, Kai M. Anaesthesia for organ donation in the brainstem dead. Anaesthesia. 2000; 55(6): 590, indexed in Pubmed: 10896635.

8. Poulton B, Garfield M. The implications of anaesthetising the brainstem dead. Anaesthesia. 2000; 55(7): 695; author reply 695-695; author reply 696, indexed in Pubmed: 10919429.

9. Young PJ, Matta BF. Anaesthesia for organ donation in the brainstem dead--why bother? Anaesthesia. 2000; 55(2): 105-106, indexed in Pubmed: 10651668.

10. Keep PJ. Anaesthesia for organ donation in the brainstem dead. Anaesthesia. 2000; 55(6): 590, indexed in Pubmed: 10866725.
11. Oram J, Murphy P. Diagnosis of death. Continuing Education in Anaesthesia Critical Care \& Pain. 2011; 11(3): 77-81, doi: 10.1093/ bjaceaccp/mkr008.

12. Citerio G, Murphy PG. Brain death: the European perspective. Semin Neurol. 2015; 35(2): 139-144, doi: 10.1055/s-0035-1547533, indexed in Pubmed: 25839722.

13. Wertheimer $P$, Jouvet $M$, Descotes J. Diagnosis of death of the nervous system in comas with respiratory arrest treated by artificial respiration. Presse Med. 1959; 67(3): 87-88, indexed in Pubmed: 13633814

14. Mollaret, $P$, Goulon, $M$. Le coma dépassé (mémoire prélininaire) Revue Neurologique. 1959; 101(1): 3-15.

15. Buchanan E. The operation: A human cardiac transplant: An interim report of a successful operation performed at Groote Schuur Hospital, Cape Town. Author: C N Barnard. S Afr Med J. 2017; 107(12): 1041-1044, indexed in Pubmed: 29262951.

16. A definition of irreversible coma. Report of the Ad Hoc Committee of the Harvard Medical School to Examine the Definition of Brain Death. JAMA. 1968; 205(6): 337-340, indexed in Pubmed: 5694976.

17. Guidelines for the determination of death. Report of the medical consultants on the diagnosis of death to the President's Commission for the Study of Ethical Problems in Medicine and Biomedical and Behavioral Research. JAMA. 1981;246(19): 2184-2186, indexed in Pubmed: 7289009.

18. Diagnosis of brain death. Statement issued by the honorary secretary of the Conference of Medical Royal Colleges and their Faculties in the United Kingdom on 11 October 1976. Br Med J. 1976; 2(6045): 1187-1188, indexed in Pubmed: 990836.

19. Criteria for the diagnosis of brain stem death. J Roy Coll Physicians Lond . 1995; 29: 381-382.

20. Siminoff LA, Burant $C$, Youngner SJ. Death and organ procurement: public beliefs and attitudes. Soc Sci Med. 2004; 59(11): 2325-2334, doi: 10.1016/j.socscimed.2004.03.029, indexed in Pubmed: 15450707.

21. Kerridge $\mathrm{IH}$, Saul $\mathrm{P}$, Lowe $\mathrm{M}$, et al. Death, dying and donation: organ transplantation and the diagnosis of death. J Med Ethics. 2002; 28(2): 89-94, indexed in Pubmed: 11934936.

22. Pascal B. Pascal's Pensées. E.P. Dutton, New York 1958: 272

23. Truog R. Personal communication. 2018.

24. Miller F, Truog R. Death, dying, and organ transplantation reconstructing medical ethics at the end of life. 2011, doi: 10.1093/acprof:oso/9780199739172.001.0001.

\section{Corresponding author:}

Gali Katznelson

Harvard Medical School

Pain Research Unit, Toronto General Hospital

200 Elizabeth Street, Toronto, ON Canada

e-mail:Gali_Katznelson@hms.harvard.edu

Received: 5.01.2018

Accepted: 28.05.2018 